\title{
The impact of orthodontic treatment needs related to dental health on the oral health-related quality of life of dental students
}

\author{
Fatima A. Elmahgoub ${ }^{1}$ and Amal H. Abuaffan ${ }^{2}$ \\ ${ }^{1}$ University of Medical Sciences and Technology, Khartoum, Sudan \\ ${ }^{2}$ Department of Orthodontics and Pedodontics, University of Medical Sciences and Technology, Khartoum, Sudan
}

\begin{abstract}
Background: Orthodontic treatment, unlike other variety of treatment, depends not only on the clinician, but also on the patients' point of view. Patients and dentists differ in their evaluation of oral health and the demand for treatment is mostly related to personal concern about appearance and other psychosocial factors. The aim of this study was to assess the impact of orthodontic treatment needs as related to dental health on the oral health-related quality of life of dental students.

Materials and methods: A cross-sectional study for a random sample of 100 2nd-5th year dental students aged 17-23 years was obtained from the University of Medical Sciences and Technology in Sudan, Alginate impression material, was taken, the cast of each students was studied and measured for different malocclusion traits and each student was assessed for orthodontic treatment need using the Dental Health Component of the Index of Orthodontic Treatment Needs by taking photographs of the dentition. Each subject was also given an Oral health-related quality to life questionnaire to complete: The Oral Health Impact Profile (OHIP)

Results: In this sample, the oral health- related quality of life was generally overall good. Those with definitive need for treatment showed higher impacts on oral health in relation to functional limitation and physical pain, than those who had borderline need, little need, or no need for treatment. Males with Borderline and definite need for treatment generally showed higher impacts on Oral Health than the female counterparts. This however was not statistically significant.
\end{abstract}

Conclusion: Malocclusion does not seem to affect the oral health-related quality of life to a significant degree.

\section{Introduction}

Now that we are in the $21^{\text {st }}$ century, orthodontics has become highly popular amongst various age groups [1]. In order to categorize and prioritize treatment, many occlusal indices have been developed based on the severity of the malocclusion and the adverse effects it has on oral health [2]. Orthodontic treatment, however, unlike other forms of treatment, depends not only on the clinician, but also on the patients' point of view [3].

Patients and dentists differ in their evaluation of oral health and the demand for treatment is mostly related to personal concern about appearance and other psychosocial factors. It was found that the decision to have treatment is not just based on the severity of malocclusion, but also on the patient's desire to improve appearance [4].

Recently, researchers and clinicians have placed more focus on patients' own perceptions of oral health status and oral health care systems to understand their needs, fulfillment with treatment, and ultimately the perceived overall quality of health systems [5-7].

A systematic review of 23 articles performed by Zhijian Liua indicated a modest association between malocclusion and the need for orthodontic treatment with quality of life [8].

The "oral health-related quality of life" is a specific concept and has been defined as "the absence of negative impacts of oral conditions on social life and a positive sense of dentofacial self-confidence [9]".
More attention is needed in understanding the physical, social, and psychological impact of malocclusion on oral health-related quality of life since it provides more understanding of the demand for orthodontic treatment beyond clinician limits. Consequently the use of the Oral health-related quality of life is recommended for orthodontists to supplement clinical findings, since its outcome doesn't essentially correlate with such objective findings [5].

Most studies of psychosocial aspects of malocclusions have been undertaken in developed countries, where people are more likely to have their basic needs met and orthodontic treatment is partially offered in public health services. However, in underdeveloped and developing countries, the relationship between malocclusion, esthetic impact, and quality of life is largely unexplored [10].

The Dental Health Component of the Index of Orthodontic Treatment Needs (IOTN-DHC) classifies malocclusions based on particular occlusal features which are considered important for dental

Correspondence to: Dr. Amal H. Abuaffan, BDS, MSc. Associate Professor, Department of Orthodontic, University of Medical Sciences and Technology, Khartoum, Sudan, Tel: 00249912696035; E-mail: amalabuaffan@yahoo.com

Key words: dental health, malocclusion, quality of life, orthodontic treatment needs, oral health-related quality of life, oral health impact profile

Received: September 21, 2015; Accepted: October 20, 2015; Published: October 23, 2015 
health. It has 5 severity levels that records the dental health need for orthodontic treatment. Those with a score of 1 are labeled as having no treatment needed, 2 as little treatment needed, 3 as borderline treatment needed, and 4 and 5 as treatment required $[11,12]$.

The Oral health impact profile (OHIP) is widely used to measure dental outcomes in terms of the impact on quality of life related to oral health. It was designed to be applied to various oral conditions. The items in the OHIP are assembled into 7 domains: functional limitation, physical pain, psychological discomfort, physical disability, psychological disability, social disability, and handicap [13].

Many previous studies reported a significant association between malocclusion and Oral Health Related Quality of Life (OHRQoL) [2,5,14-16].

This study aims to answer the following questions: Do various orthodontic treatment needs related to dental health have an impact on the oral health-related quality of life? Does gender significantly affect the oral health-related quality of life? And is there a difference of OHIP scores between genders in relation to the IOTN-DHC?

\section{Materials and methods}

A cross-sectional study was carried out in the Academy Charity Teaching Hospital (ACTH), University of Medical Sciences and Technology (UMST), Faculty of Dentistry, Khartoum, from November 2012 to February 2013.

Permission and authorization was obtained from UMST. All participants were given a concise explanation about the aims of the study and the methods that would be carried out. Each participant was then asked to sign a consent form before participation in order to obtain informed consent.

This research included $2^{\text {nd }}, 3^{\text {rd }}, 4^{\text {th }}$, and $5^{\text {th }}$ year dental students in the University of Medical Sciences and Technology. $1^{\text {st }}$ years were not included because they were not present in the Academy Charity Teaching Hospital (ACTH) at the time. The following groups of subjects were excluded from the study:

-Students who had active orthodontic treatment.

-Students who have had previous orthodontic treatment.

The sampling technique used was Stratified random sampling.

The desirable sample size was $\mathrm{N}=100$ students

\section{Data collection techniques}

Each batch was informed about the aim of the study and all the steps which were required to collect the data in the lecture room, and the ones who have received orthodontic treatment or were on active orthodontic treatment were checked out of the registration sheet.

The study population was divided into two strata, one consisting of males, and the other females. The individuals who have met the inclusion criteria were chosen randomly from a registration sheet.

Once consent had been obtained, each individual was first assessed for orthodontic treatment needs using the dental health component of the Index of orthodontic treatment need (IOTN-DHC).

Each subject was seated on a dental chair, and an impression, using a stock tray and Alginate impression material, was taken, washed out and disinfected, then casted using plaster in the university dental lab. Subsequently, the cast was studied and measured using the MOCDO convention to identify the most severe trait in each individual where:

$$
\begin{aligned}
& \mathrm{M}=\text { Missing teeth } \\
& \mathrm{O}=\text { Overjet } \\
& \mathrm{C}=\text { Crossbite } \\
& \mathrm{D}=\text { Displacement of contact points } \\
& \mathrm{O}=\text { Overbite }
\end{aligned}
$$

A grade was given on the basis of the single most severe feature of the malocclusion.

The index has been validated as follows:

Grade 1: No treatment needed

Grade 2: Minimal treatment needed

Grade 3: Moderate treatment needed

Grade 4 and 5: Definite treatment needed

Secondly, the Oral Health-Related Quality of Life was determined by giving each subject a questionnaire to complete with the examiner sitting by the students for explanation of any questions if needed. The questionnaire was the Oral Health Impact Profile (OHIP) which is composed of 49 questions associated with oral health. The participants were asked to point out on a five-point Liker scale how often each problem was experienced, within a reference period of 12 months. Response categories for the five-point scale are: "Very often", "Fairly often", "Occasionally", "Hardly ever" and "Never". For three questions that ask about denture-related problems (numbers 9, 18 and 30), a response option was provided for non-wearers of dentures to indicate that these questions do not apply to them.The OHIP scores were then obtained.

\section{Data processing and analysis}

The data was processed and analyzed using computer software programs SPSS (Statistical Package for Social Sciences) version 17.

Index of Orthodontic Treatment Needs (IOTN): For data entry, the IOTN (Dental Health Component) was entered according to the grades which have been presented.

Oral Health Impact Profile (OHIP): The OHIP scores were entered as follows: Responses were coded 0 (never or not applicable), 1 (hardly ever), 2 (occasionally), 3 (fairly often) or 4 (very often). Blank entries were entered as missing values, which subsequently were recorded with the mean value of all valid responses to the corresponding question.

During data processing, coded responses for each question in the OHIP were multiplied by the corresponding weight for each question and the products summed within each dimension to give seven subscale scores, each with a potential range from zero (no impact) to 40 (all impacts reported "very often").

The results were then analyzed and correlated with those of the Index of orthodontic treatment needs (IOTN) and final results were obtained and presented in tables and figures. The tests which were used during analysis were Chi-squared test, and ANOVA test.

\section{Results}

Figure 1 shows the gender distribution in the study; the majority of the study sample was females ( $78 \%$ ), while $22 \%$ were males. 


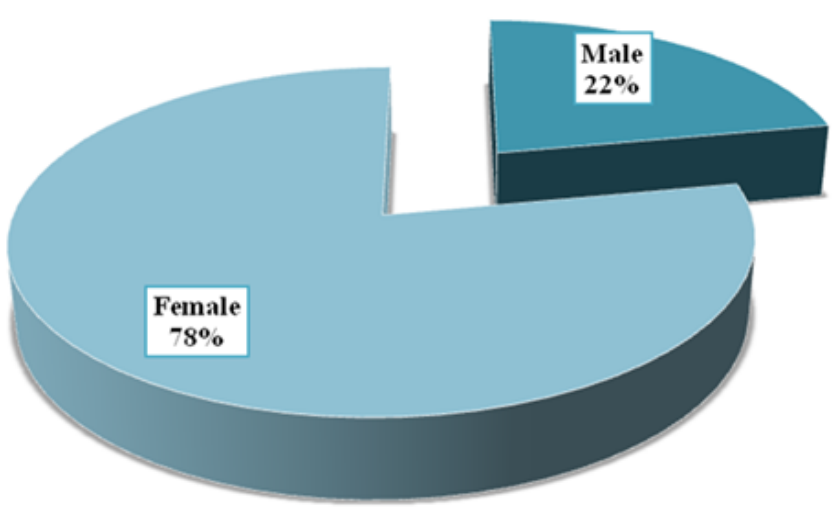

Figure 1. Distribution of the study sample according to (Gender).

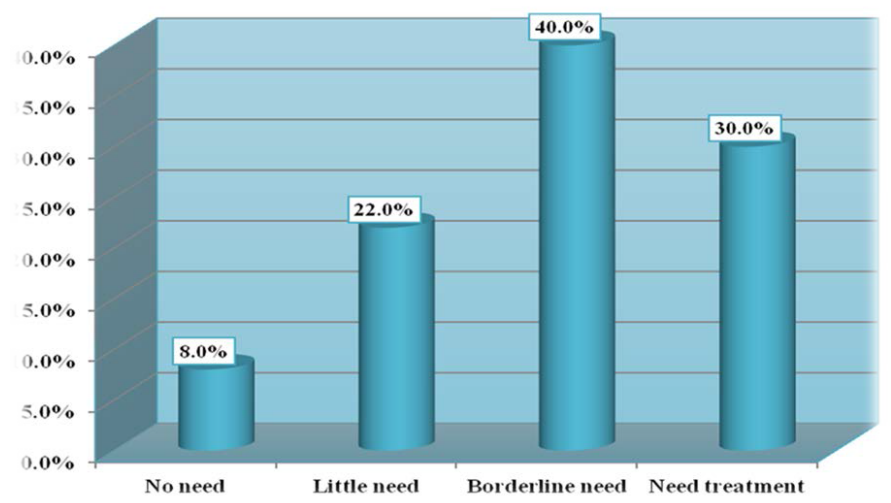

Figure 2. Distribution of the study sample according to (Index of Orthodontic Treatment Needs (Dental Health Component)-IOTN (DHC)).

Figure 2 shows the distribution of the study sample according to Index of Orthodontic Treatment needs (Dental Health Component). In the figure, it is clear that most of the sample (40\%) showed a borderline need for treatment, while $30 \%$ showed definitive need, $22 \%$ little need, and $8 \%$ no need for treatment.

Figure 3 shows the distribution of the study sample according to (Index of Orthodontic Treatment Needs (Dental Health Component)IOTN (DHC)) in relation to gender. Most of the male population in this sample (54.5\%) had borderline need for treatment, 36.4\% had definitive need, and $9.1 \%$ didn't need treatment, while $0 \%$ of males had little need for treatment. Females however, were more evenly distributed. $28.2 \%$ had definitive need for treatment, $35.9 \%$ had borderline need, $28.2 \%$ little need, and $7.7 \%$ no need.

Table 1 shows The Oral health Impact Profile scores (mean \pm S.D) in relation with Index of Orthodontic Treatment Needs (Dental Health Component)-IOTN (DHC) Those with definitive need for treatment showed higher impacts on oral health in relation to functional limitation and physical pain, than those who had borderline need, little need, or no need for treatment. Nonetheless, this was not statistically significant.

Figure 4 shows The Oral health Impact Profile scores in relation to gender in those who had no need for treatment according to the Index of Orthodontic Treatment Needs (Dental Health Component). Males who had no need of treatment scored higher in functional limitation than females, while females had a higher overall OHIP score. This however, was not statistically significant.

Figure 5 OHIP scores in relation to gender in those who had little need for treatment according to the Index of Orthodontic treatment needs- Dental Health Component. None of the males in the sample (0\%) had little need for treatment. This figure shows that females with

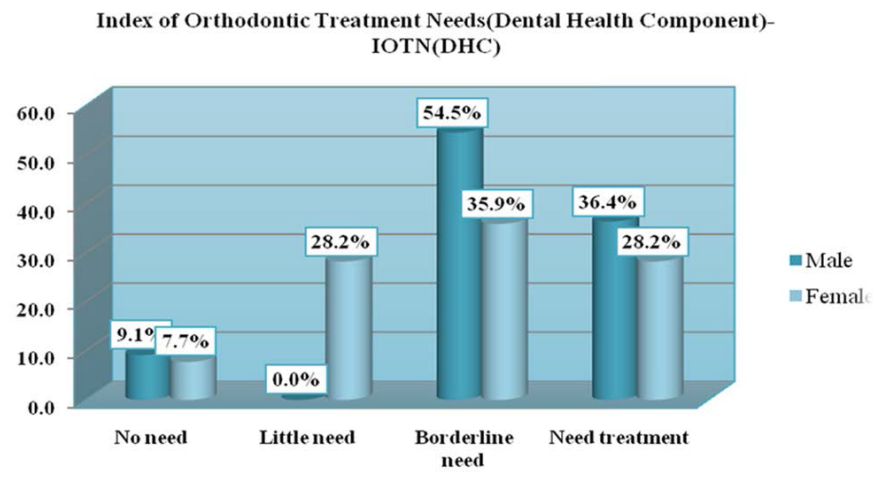

Figure 3. Distribution of the study sample according to (Index of Orthodontic Treatment Needs (Dental Health Component)-IOTN (DHC)) in relation to gender.

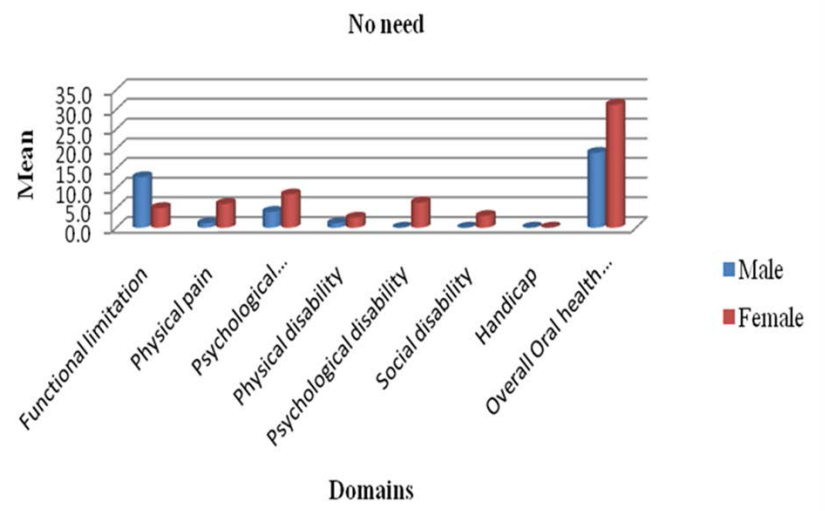

Figure 4. OHIP scores in relation to gender in those who had no need for treatment according to (Index of Orthodontic Treatment Needs (Dental Health Component)-IOTN (DHC)).

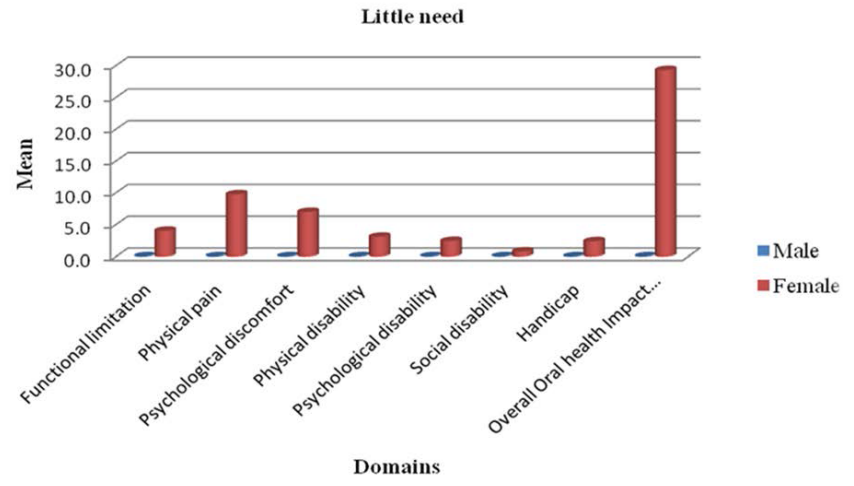

Figure 5. OHIP scores in relation to gender in those who had little need for treatment according to the Index of Orthodontic treatment needs- Dental Health Component (IOTNDHC). 
Table 1. The Oral health Impact Profile scores (mean \pm S.D) in relation with Index of Orthodontic Treatment Needs (Dental Health Component)-IOTN (DHC).

\begin{tabular}{|c|c|c|c|c|c|c|c|c|c|}
\hline & & $\begin{array}{l}\text { Functional } \\
\text { limitation }\end{array}$ & $\begin{array}{c}\text { Physical } \\
\text { pain }\end{array}$ & $\begin{array}{c}\text { Psychological } \\
\text { discomfort }\end{array}$ & $\begin{array}{l}\text { Physical } \\
\text { disability }\end{array}$ & $\begin{array}{c}\text { Psychological } \\
\text { disability }\end{array}$ & $\begin{array}{c}\text { Social } \\
\text { disability }\end{array}$ & Handicap & $\begin{array}{l}\text { Overall Oral health } \\
\text { Impact Profile scores }\end{array}$ \\
\hline \multirow{5}{*}{$\begin{array}{l}\text { Index of Orthodontic } \\
\text { Treatment Needs } \\
\text { (Dental Health } \\
\text { Component)- } \\
\text { IOTN(DHC) }\end{array}$} & No need & $6.9 \pm 4.1$ & $4.8 \pm 5.5$ & $7.3 \pm 5.6$ & $2.2 \pm 0.9$ & $4.7 \pm 9.5$ & $2.2 \pm 4.5$ & $0.0 \pm 0.0$ & $28.2 \pm 22.7$ \\
\hline & Little need & $4.0 \pm 3.1$ & $9.7 \pm 5.7$ & $7.0 \pm 6.8$ & $3.1 \pm 2.3$ & $2.4 \pm 3.6$ & $0.7 \pm 2.5$ & $2.4 \pm 4.0$ & $29.3 \pm 21.1$ \\
\hline & Borderline need & $7.4 \pm 3.7$ & $8.9 \pm 6.2$ & $9.3 \pm 8.1$ & $4.8 \pm 4.4$ & $5.0 \pm 8.4$ & $3.6 \pm 5.9$ & $3.3 \pm 4.5$ & $41.3 \pm 28.8$ \\
\hline & Need treatment & $7.4 \pm 4.2$ & $11.6 \pm 5.8$ & $7.8 \pm 6.5$ & $3.6 \pm 4.3$ & $2.5 \pm 4.1$ & $1.6 \pm 2.7$ & $2.7 \pm 5.5$ & $37.0 \pm 24.7$ \\
\hline & P-Value & 0.097 & 0.213 & 0.828 & 0.459 & 0.606 & 0.311 & 0.612 & 0.580 \\
\hline
\end{tabular}

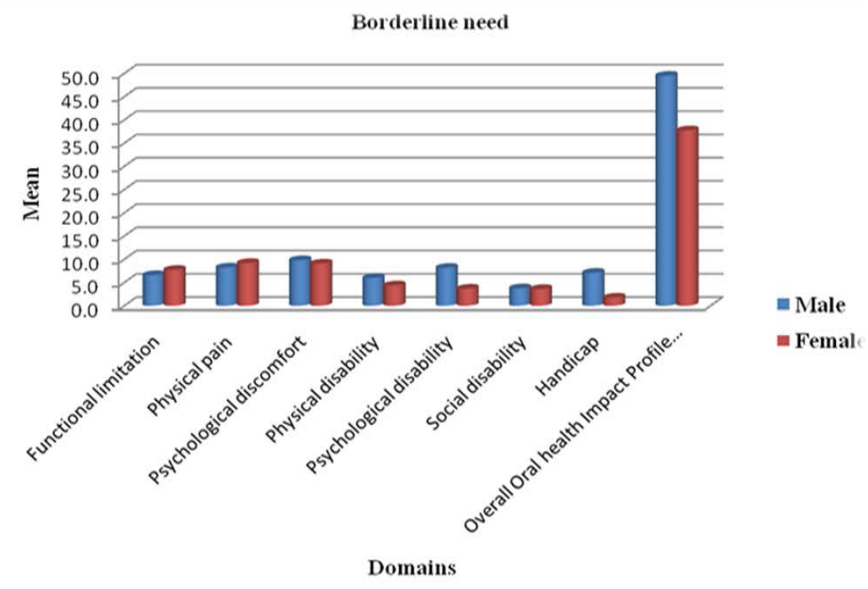

Figure 6. OHIP scores in relation to gender in those who had borderline need for treatment according to (Index of Orthodontic Treatment Needs (Dental Health Component)-IOTN (DHC)).

little need for treatment scored higher in physical pain than other domains.

Figure 6 OHIP scores in relation to gender in those who had borderline need for treatment according to the Index of Orthodontic Treatment Needs (Dental Health Component). This figure shows that both genders with borderline need for treatment scored higher in physical pain and psychological discomfort than other domains.

Males scored higher than females in psychological disability and handicap, while both genders had similar scores for social disability. Males also showed a higher overall OHIP score than females. Nonetheless, this was not statistically significant.

Figure 7 shows that females with definitive need for treatment scored highest in physical pain than other domains, while males of the same treatment need scored highest in psychological discomfort than other domains.

Males scored higher than females in functional limitation, physical disability, and handicap, as well as showing a higher overall OHIP score than females.

\section{Discussion}

It has become widely accepted that assessment of the oral healthrelated quality of life plays an important role in clinical practice $[3,5,7,17-21]$ this is particularly true in the treatment of malocclusion.

The results of this study showed that the orthodontic treatment needs related to dental health didn't significantly affect the oral health-

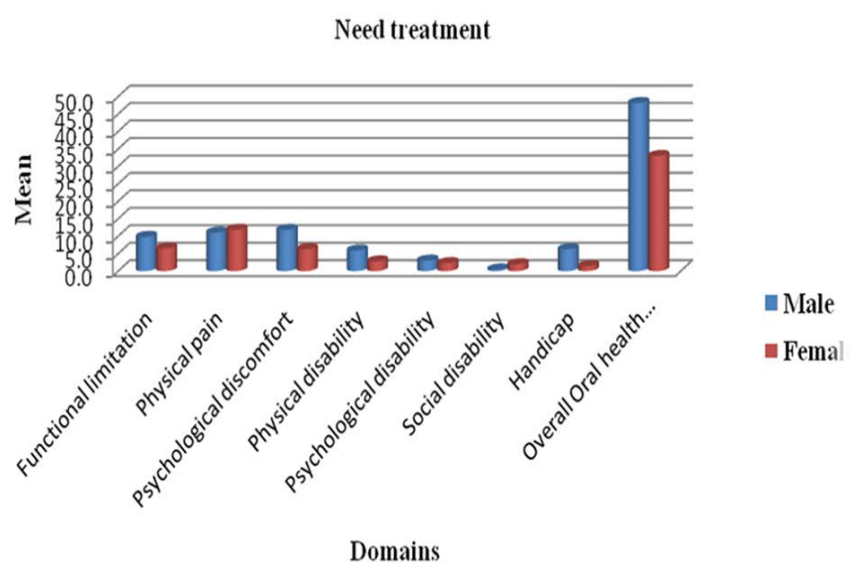

Figure 7. OHIP scores in relation to gender in those who had definitive need for treatment according to (Index of Orthodontic Treatment Needs (Dental Health Component)-IOTN (DHC)).

related quality of life, which were consistent with the results of Vig et al. [22] and Taylor et al. [4] who carried out a study on 293 children aged 11 to 14 recruited from orthodontic and pediatric dental clinics at the University of Washington and a community health clinic in Seattle. Both of these studies examined the effect of malocclusion and its treatment on the oral health-related quality of life. Remarkably, similar results were obtained in this study despite the different backgrounds and sample size.

On the other hand, the results of this study differed from the results of numerous studies $[2,5,14-16]$ which found a significant negative effect of malocclusion on the oral health-related quality of life.

Liu et al. performed a systematic review of the literature on the impact of malocclusion/orthodontic treatment needs on the oral health-related quality of life [2]. Hassan and Amin assessed the effect of different orthodontic treatment needs on the oral health-related quality of life of 366 young Saudi Arabian adult orthodontic patients [5]. Klages et al. examined the relationship between dental esthetics and oral health-related quality of life in a group of 148 German university students [16]. All of the above studies were carried out with larger sample sizes and assessed wider variations of malocclusions and this may be the cause of variation of their results from the present study.

When comparing OHIP scores in the present study in relation to gender in those who had definitive need for treatment according to the IOTN-DHC, it was found that females with definitive need for treatment scored highest in physical pain than other domains, while males of the same treatment need scored highest in psychological 
discomfort. This again, goes against similar studies which have been conducted $[5,14]$.

An interesting feature of the results of this study was that, although the responses indicated no association between orthodontic treatment needs and oral health-related quality of life, it is clear that the standard deviations were large when the OHIP was assessed with IOTN-DHC, as well as gender. This may indicate that malocclusion status alone didn't determine the oral health-related quality of life and that other factors possibly contributed to the impacts on oral health in this study. Other studies controlled confounding factors such as that carried out by Foster Page et al. [17] where the caries index was accounted for using the DMFT score.

Some studies focused only on aesthetics including Klages et al. [16] and Foster Page et al. [17]. Malocclusion is as much an anatomical phenomenon as it is a social one, and therefore leaving out one or the other doesn't give the true essence of the impact.

It has been noticed that orthodontic treatment has become more widespread and accessible among the Sudanese population than it had been in previous years, due to increased public awareness, university clinics, and an increased number of orthodontists.

The current cross-sectional study to our knowledge was the first in Sudan to use both The Oral Health Impact Profile (OHIP), and the Index of Orthodontic Treatment Needs (Dental Health Component) to investigate the effects of malocclusion on the oral health-related quality of life of dental students, taking advantage of the university dental lab facility for taking impressions and casting them. There was no room for selection bias because the subjects were randomly selected. The OHIP was used out of all the other oral health- related quality of life measures because it has been used in many studies $[2,5,13,14]$ to assess the relationship between malocclusion and oral health-related quality of life, and it is concerned with three functional status dimensions: social, psychological and physical which represent four of the seven dimensions of quality of life [13].

However, some limitations should be addressed. Due to the constraint of time and cost, the sample size was small, and may not have shown a clear association because of the variety of malocclusions in the general population. Therefore, a larger sample may be required to support this research. The subjects were dental students themselves from UMST, faculty of Dentistry who may have had better access to dental care and more knowledge in the field of dentistry. That is why the results might not be generalized to the population of young Sudanese adults requiring orthodontic treatment.

\section{Conclusion}

Orthodontic treatment needs as related to dental health per se doesn't impact the oral health related quality of life, but it plays a role. Males with definite and borderline need for treatment generally showed significantly higher OHIP scores in the handicap domain than the females in that group. They also showed higher overall OHIP scores. Females, on the other hand, with no need for treatment had more impacts to oral health overall, than males who also had no need for treatment.

\section{References}

1. Mark G (2005) Hans and Manish Valiathan. Bobbing for Apples in theGarden of Eden. Semin Orthod 11:86-93.

2. Liu Z, McGrath C, Hägg U (2009) The impact of malocclusion/orthodontic treatment need on the quality of life. A systematic review. Angle Orthod 79: 585-591. [Crossref]
3. Hassan AH (2006) Orthodontic treatment needs in the western region of Saudi Arabia: a research report. Head Face Med 2: 2. [Crossref]

4. Taylor KR1, Kiyak A, Huang GJ, Greenlee GM, Jolley CJ, et al. (2009) Effects of malocclusion and itstreatment on the quality of life of adolescents. Am J Orthod Dentofacial Orthop 136:382-92. [Crossref]

5. Hassan AH, Amin Hel-S (2010) Association of orthodontictreatment needs and oral health-related quality of life in young adults. Am J Orthod Dentofacial Orthop 137:42-7. [Crossref]

6. Bedi R, Gulati N, McGrath C (2005) A study of satisfaction with dental services among adults in the United Kingdom. Br Dent $J$ 198: 433-437. [Crossref]

7. McGrath C, Bedi R (1999) The value and use of 'quality of life' measures in the primary dental care setting. Prim Dent Care 6: 53-57. [Crossref]

8. Palomares NB, Celeste RK, Oliveira BH, Miguel JA (2012) How does orthodontic treatment affect young adults' oral health-related quality of life? Am J Orthod Dentofacial Orthop 141: 751-758. [Crossref]

9. Cunningham SJ (2007) Catherine O’Brien. Quality of life andorthodontics. Sem in Orthod 13:96-103.

10. Ramos-Jorge ML, Vieira-Andrade RG, Martins-Júnior PA, Cordeiro MM, RamosJorge J, et al. (2012) Level of agreement between self-administered and intervieweradministered $\mathrm{CPQ}_{8-10}$ and $\mathrm{CPQ}_{1-14}$. Community Dent Oral Epidemiol 40: 201-209. [Crossref]

11. Marques LS, Ramos-Jorge ML, Paiva SM, Pordeus IA (2006) Malocclusion: esthetic impact and quality of life among Brazilian schoolchildren. Am J Orthod Dentofacial Orthop 129: 424-427. [Crossref]

12. Brook PH, Shaw WC (1989) The development of an index of orthodontic treatment priority. Eur J Orthod 11: 309-320. [Crossref]

13. Johansson AM, Follin ME (2009) Evaluation of the Dental Health Component, of the Index of Orthodontic Treatment Need, by Swedish orthodontists. Eur J Orthod 31: 184-188. [Crossref]

14. Slade GD, Spencer AJ (1994) Development and evaluation of the OralHealth Impact Profile. Community Dent Health 11: 3-11. [Crossref]

15. de Oliveira CM, Sheiham A (2004) Orthodontic treatment and its impacton oral healthrelated quality of life in Brazilian adolescents. J Orthod 31:20-27. [Crossref]

16. Klages U, Bruckner A, ZentnerA (2004) Dental aesthetics, self-awareness, and ora health-related quality of life in young adults. Eur J Orthod 26: 507-514. [Crossref]

17. Foster Page LA, Thomson WM, Jokovic A, Locker D (2005) Validation of the Child Perceptions Questionnaire (CPQ 11-14). J Dent Res 84: 649-652.[Crossref]

18. Spalj S, Slaj M, Varga S, Strujic M, Slaj M (2010) Perception of orthodontic treatment need in children and adolescents. Eur J Orthod 32: 387-394. [Crossref]

19. Shivakumar KM, Chandu GN, Subba Reddy VV, Shafiulla MD (2009) Prevalence of malocclusion and orthodontic treatment needs among middle and high school children of Davangere city, India by using Dental Aesthetic Index. J Indian Soc Pedod Prev Dent 27: 211-218. [Crossref]

20. Shivakumar K, Chandu G, Shafiulla M (2010) Severity of Malocclusion and Orthodontic Treatment Needs among 12- to 15-Year-Old School Children of Davangere District Karnataka, India. Eur J Dent 4: 298-307. [Crossref]

21. Slade GD (2012) Oral health-related quality of life is important for patients, but what about populations? Community Dent Oral Epidemiol 40: 39-43. [Crossref]

22. KWL Vig, Allen F, Wyatt W, Misty L (2007) Quality of Orthodontic Treatment. Semin Orthod 13: 81-87.

Copyright: (C2015 Elmahgoub FA. This is an open-access article distributed under the terms of the Creative Commons Attribution License, which permits unrestricted use, distribution, and reproduction in any medium, provided the original author and source are credited. 